\title{
Incidencia de factores socioculturales como ruralidad y género en el rendimiento académico del primer semestre de estudiantes de la carrera de cinesiología
}

\author{
José Alejandro Iturra-González, Rubén Eduardo Soto-Fuentes
}

Objetivo. Determinar si las variables socioculturales como 'origen rural', medido con el nuevo índice de ruralidad del Centro Latinoamericano para el Desarrollo Rural (Rimisp), y el 'género' se relacionan con rendimiento académico, entendido como promedio numérico tras el primer semestre lectivo.

Sujetos y métodos. Se evaluó a los alumnos de la carrera de cinesiología en la Universidad Santo Tomás-Talca pertenecientes a las cohortes de 2010 y 2011. Los datos de género e índice de ruralidad se asociaron al rendimiento académico.

Resultados. No existe relación estadísticamente significativa entre rendimiento académico y género, pero sí entre índice de ruralidad y rendimiento académico $(p=0,05)$ durante el primer semestre lectivo de la carrera de cinesiología en la sede de Talca.

Conclusión. Los alumnos provenientes de localidades rurales (tipologías 1 y 2) superan en rendimiento a sus pares urbanos; el género no es un factor relevante a considerar en el rendimiento.

Palabras clave. Cinesiología. Educación. Educación intercultural. Genero. Rendimiento académico. Ruralidad.

Incidence of sociocultural factors like rurality and gender in the academic performance of the kinesiology program students

Aim. To determine if variables like rurality, measured with the new rurality index from the Latin American Centre for Rural Development (Rimisp), and gender are related with academic performance in the form of the average final mark of the first semester.

Subjects and methods. Kinesiology students from cohorts 2010 and 2011 were assessed. Data of gender and rurality were associated with academic performance.

Results. There is no relation of statistical significance between academic performance and gender. However, there is a relation of statistical significance $(p=0.05)$ between the rurality index and academic performance during the first academic semester of the kinesiology program at University of Santo Tomás-Talca.

Conclusion. Students coming from rural areas (typology 1 and 2) surpassed their urban counterparts and that gender is not a relevant factor to be considered in academic performance.

Key words. Academic performance. Education. Gender. Intercultural education. Kinesiology. Rurality.

\section{Introducción}

El rendimiento académico es un indicador del aprendizaje alcanzado por el alumno, dando cuenta de su trayectoria escolar hasta un momento determinado. Si la medida del rendimiento es adecuada, expresa incluso el nivel de conocimientos previos que posee el alumno.

Según el censo de población del año 2002, en una superficie continental de $746.767 \mathrm{~km}^{2}$ en Chile, la población asciende a 15.116.435 millones de personas: 7.668 .740 mujeres $(50,73 \%)$ y 7.447 .695 hombres $(49,27 \%)$. Esta población se distribuye en un $86,6 \%$ en zonas urbanas, mientras que el $13,4 \%$ restante vive en zonas rurales. Los autores que han estudiado la ruralidad indican que la definición oficial subestima fuertemente el tamaño poblacional del sector rural. En términos de su concentración geográfica, se observa que la mayor parte de la población reside en las regiones Metropolitana (40\%), Biobío (12,31\%) y Valparaíso (10,18\%). Bajo los criterios del Instituto Nacional de Estadísticas (INE)
Facultad de Salud. Universidad Santo Tomás. Talca, Chile.

Correspondencia:

Dr. José Alejandro Iturra González. Escuela de Cinesiología. Facultad de Salud. Universidad Santo Tomás. Avda. Carlos Schorr, 255. Comuna Talca. Talca, Chile.

E-mail:

aiturra@santotomas.cl

Agradecimientos:

César Ide, director de admisión, y María Inés Domper, directora académica, por facilitar el proceso de recogida de datos.

Conflicto de intereses: No declarado.

Conflict of interests: None declared.

(c) 2013 FEM 
y de la nueva tipología rural impulsada por el Centro Latinoamericano para el Desarrollo Rural (Rimisp), la región chilena más rural es la del Maule, y las menos rurales son las de Valparaíso y Metropolitana [1].

Estos resultados se apoyan en los hallazgos de otros estudios que cuestionan la subestimación de la ruralidad desde el punto de vista de las cifras oficiales en Chile. La Organización para la Cooperación y el Desarrollo Económicos (OCDE), durante el proceso de incorporación de Chile a ese organismo, estimó una tasa de ruralidad del 42\% [2].

La dicotomía rural-urbana es uno de los principales enfoques teóricos que plantea la existencia de un espacio tradicional y un espacio moderno, cada uno definido por características absolutas y excluyentes. Al rural se le asocian adjetivos contrarios a la idea de progreso y modernización, mientras que al urbano se lo asocia directamente con las ciudades y sus necesidades de consumo. El consenso actual entre los especialistas es a favor de la idea de un gradiente rural-urbano, en reemplazo de la visión de un contraste absoluto entre lo rural-urbano [3].

La población que reside en las áreas determinadas tradicionalmente como rurales del país presentan menores niveles de desarrollo y de bienestar; se les puede considerar un grupo socialmente vulnerable que vive en situaciones de precariedad en materia de servicios educativos, los cuales son limitados y muchas veces deficientes. La falta de espacios, estudio y opciones educativas, tanto para mujeres como para hombres, se debería quizá al aislamiento y lejanía en que viven respecto a las ciudades consideradas como polos urbanos. A pesar de que la tasa de abandono escolar y universitaria ha disminuido en los últimos diez años, sigue siendo el doble que en las zonas urbanas, con un $32 \%$ para ambos géneros, frente a un $17 \%$ en el sector urbano. Es destacable también que en el ámbito rural son más los hombres que abandonan (33\% frente a un 30\% de las mujeres) [4]. El género parece influir en las estrategias más de lo que indican las diferentes formas de abordar y procesar la información. Los datos muestran que esta interacción es muy importante para comprender la naturaleza de las diferencias de género en el aprendizaje, que no se producirían por razones genéticas, sino más bien por factores culturales y aspectos derivados de los contenidos específicos de cada tipo de tarea que fomentan o atenúan el uso (y, por tanto, desarrollo) de ciertos recursos intelectuales [5].

En el primer año de universidad, los alumnos rurales se enfrentan a problemas que surgen tanto de la transición lógica de la adolescencia-juventud co- mo de la transición escuela-universidad. Inevitablemente se apareja a un sentido de pérdida y, al mismo tiempo, de nuevas oportunidades. La forma en cómo se equilibran las pérdidas y oportunidades disminuye el grado de tensión, que es crucial para el estudiante que ingresa en la universidad [6].

En este contexto, el presente estudio tiene por objetivo caracterizar a los estudiantes de la Escuela de Cinesiología de la Universidad Santo Tomás-Talca y establecer las asociaciones entre ruralidad y genero frente a su rendimiento académico en el primer semestre universitario.

\section{Sujetos y métodos}

El estudio se realizó caracterizando la población de estudiantes de las cohortes de 2010 y 2011 de la carrera de cinesiología de la Universidad Santo TomásTalca. En ellos se identificaron: género (masculino o femenino), rendimiento académico y origen según la localidad y comuna a la que pertenecían.

\section{Participantes}

Se incluyó a todos los estudiantes de la carrera de cinesiología de la Facultad de Salud de la Universidad Santo Tomás-Talca de las cohortes de 2010 y 2011, en sus actividades del primer semestre de dichos años. Se excluyó a todos aquellos sujetos que abandonaron sus estudios de forma definitiva o temporal durante ese periodo. Además, se excluyó a quienes convalidaron sus asignaturas correspondientes al primer semestre y a quienes no se presentaron a sus exámenes finales.

\section{Metodología}

Se midieron las siguientes variables independientes: género y grado de ruralidad. El grado de ruralidad se definía como un gradiente rural-urbano basado en el concepto de que existen grados y tipos distintos de ruralidad. Operacionalmente se definió según la tipología del Centro Latinoamericano para el Desarrollo Rural (Rimisp).

En el estudio se consideraron como individuos con un origen sociocultural rural los que pertenecían a las tipologías 1 y 2 , mientras que aquellos que viven en las ciudades altamente pobladas, con un alto capital humano y con matrices económicas diversificadas fueron considerados urbanas.

El rendimiento académico se definió según las notas finales obtenidas durante el primer semestre, cuantificado por el sistema CLAS como promedio 
Tabla. Análisis de varianza factorial del rendimiento promedio entre estudiantes de primer semestre de la carrera de cinesiología.

\begin{tabular}{lccccc}
\hline & $\begin{array}{c}\text { Suma de } \\
\text { cuadrados }\end{array}$ & gl & $\begin{array}{c}\text { Cuadrados } \\
\text { medios }\end{array}$ & $F$ & $p$ \\
\hline Origen & 1,946 & 1 & 1,946 & 4,941 & 0,029 \\
\hline Género & 0,001 & 1 & 0,001 & 0,003 & 0,956 \\
\hline Origen $\times$ Género & 0,766 & 1 & 0,766 & 1,944 & 0,166 \\
\hline Error & 38,992 & 99 & 0,394 & & \\
\hline
\end{tabular}

ponderado de todas las asignaturas cursadas durante el primer semestre para las cohortes de 2010 y 2011. Operacionalmente, esta variable se expresó en nota de 1,0 a 7,0, considerando sólo un decimal.

Como un antecedente adicional, se consignó el número de asignaturas suspendidas en el primer semestre, cuantificado por el sistema CLAS. Esta variable se expreso en porcentaje.

La información de los estudiantes se obtuvo mediante el ingreso al sistema de gestión interna de la Universidad Santo Tomás, denominado CLASS, que contiene los datos académicos de los estudiantes.

\section{Análisis estadístico}

Para comparar el rendimiento de los alumnos de cinesiología según el género de cada individuo se utilizó un análisis de varianza de una vía (ANDEVA). Del mismo modo, se comparó el rendimiento de los alumnos según su origen sociocultural (rural o urbano) mediante un análisis similar (ANDEVA).

Los valores de los rendimientos obtenidos se calcularon mediante un análisis de varianza de tipo factorial, en donde se utilizaron el género y el origen sociocultural como posibles factores que darían cuenta de la variación observada según Zar [7].

Los análisis estadísticos se realizaron utilizando el porgrama estadístico Systat v. 12.0, considerando una significación $p>0,05$.

\section{Resultados}

Un total de 103 alumnos cursaron el primer semestre de la carrera de cinesiología en la Universidad Santo Tomás-Talca. Un 59\% pertenecían al sexo femenino, y los restantes, al sexo masculino. De los alumnos evaluados, los que procedían de un gradien-
Figura. Rendimiento promedio de los estudiantes de cinesiología según su origen sociocultural y género. Las líneas sobre las barras representan 1 error estándar.

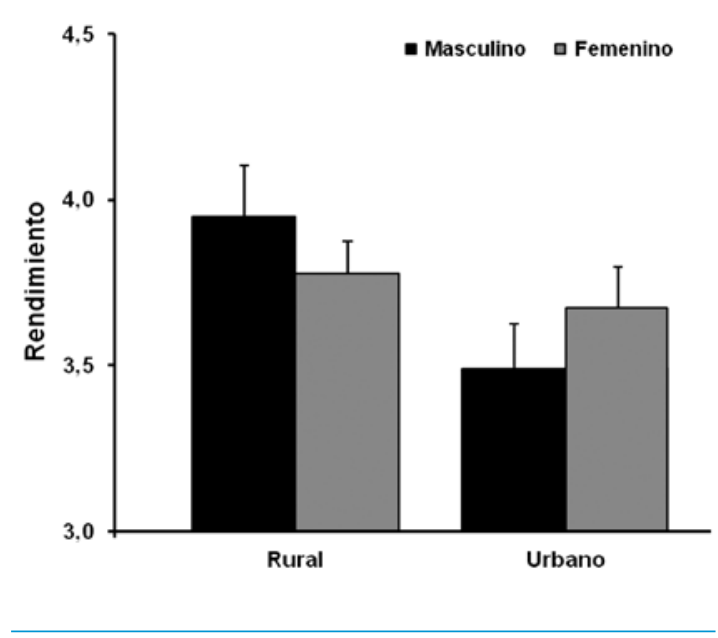

te considerado como rural constituyeron un $48,5 \%$, y los restantes presentaban un origen urbano.

Los estudiantes evaluados no mostraron diferencias significativas al considerar tanto su edad como su rendimiento previo, durante la enseñanza media. Esto fue válido al considerar comparaciones previas entre géneros y al analizar las variables según su procedencia (urbana o rural).

El rendimiento promedio de los estudiantes de la carrera de cinesiología no presentó diferencias significativas entre los de sexo femenino y masculino (ANDEVA: $F=0,185 ; \mathrm{gl}=1 ; p=0,67$ ). Las estudiantes de sexo femenino presentaron un porcentaje medio de aprobación de $53,82 \pm 26,07 \%$, mientras que los individuos de sexo masculino mostraron una aprobación media de 50,00 $\pm 27,30 \%$.

Los estudiantes de procedencia rural presentaron un rendimiento promedio de 3,84 (error estándar $=0,08$ ), mientras que los individuos de procedencia urbana mostraron un rendimiento promedio que alcanzó 3,58 (error estándar = 0,09). Al comparar el rendimiento promedio de los estudiantes de cinesiología según su origen sociocultural se observaron diferencias significativas entre los individuos provenientes del ambiente rural y del urbano (ANDEVA: $F=4,105 ; \mathrm{gl}=1 ; p=0,045)$.

Al estudiar el rendimiento promedio de los estudiantes mediante un análisis de varianza factorial se observó que sólo el origen sociocultural mostró diferencias significativas, mientras que la variable 
género y la interacción entre ambos factores no presentaron valores significativos (Tabla).

$\mathrm{Al}$ analizar la figura, se observa un patrón diferente al comparar el rendimiento de los alumnos provenientes del gradiente rural con los de origen urbano. En el caso de los estudiantes provenientes del gradiente rural, los individuos de sexo masculino presentaron un rendimiento promedio ligeramente mejor en comparación con los de sexo femenino, aunque esta tendencia no fue estadísticamente significativa $(t=0,98 ; \mathrm{gl}=1 ; p=0,331)$. En el caso de los alumnos de zona urbana, el patrón de rendimiento es distinto porque en este caso fueron las mujeres quienes presentaron un leve mejor rendimiento en comparación con los individuos de sexo masculino, aunque esta tendencia no resultó estadísticamente significativa $(t=1,0 ; \mathrm{gl}=1 ; p=0,32)$.

\section{Discusión}

Cuando se analiza la bibliografía en relación con los factores que influyen en el rendimiento académico, existe una clara dicotomía entre aquellos que asignan diferentes valores a datos denominados endógenos y a factores denominados exógenos; estos, de una $u$ otra manera, actúan condicionando el rendimiento de los estudiantes, en especial en esta etapa compleja de transición entre su escuela o colegio y su primer año de universidad. Lo más probable es que ninguno actué de manera independiente, sino que más bien se trate de una interacción mediada y recíproca de ambos factores [8].

La controversia radica en que no existe una denominación única para temas como rendimiento y ruralidad; se trata de conceptos complejos en su definición, puesto que el rendimiento se ha considerado de diferentes formas: número de asignaturas aprobadas, notas, promedios, medias ponderadas, etc.

Una de las ventajas de este estudio radica en el uso de una nueva tipología propuesta por Berdegué et al [4], que considera el nuevo concepto de gradiente rural-urbano y asigna importancia a factores olvidados en las definiciones tradicionales de ruralidad (en las que prima únicamente lo demográfico). En esta tipología se incorporan datos como demografía, accesibilidad (tiempo de viaje al centro urbano más cercano), capital humano (porcentaje de población con educación superior universitaria), servicios y datos económicos. Ello posibilita un acercamiento más real al concepto de ruralidad.

Los jóvenes rurales (tipologías 1 y 2), cuando se compararon con sus pares urbanos, demostraron un rendimiento significativamente superior, lo que concuerda con las diferencias encontradas por Carrión-Pérez [9] en estudiantes cubanos de medicina, en los cuales la variable demográfica de procedencia fue relevante como predictora de rendimiento.

Cabe destacar a ciertos autores cuyos resultados se contraponen a los nuestros. Ellos no le asignan significado a la variable de origen demográfico, sólo de manera inversa a la edad (quizá esto pueda explicarse por la metodología utilizada para evaluar la residencia, seguramente establecida por tipologías oficiales) $[10,11]$. A pesar de lo anterior, y en concordancia con los estudios [10,11] sobre género y rendimiento, no han obtenido diferencias estadísticamente significativas que permitan considerar el género como una variable que explique la variabilidad observada en el rendimiento.

Nuestros hallazgos permiten asignar un rol relevante al origen de los sujetos en el rendimiento porque los estudiantes procedentes de zonas rurales pertenecen a una cultura diferente, en donde la responsabilidad personal y el compromiso con los deberes se adquieren a temprana edad.

Lo anterior es refrendado por las nuevas tendencias de formación de jóvenes en las universidades europeas, que favorecen el interés de la educación centrada en el alumno y valoran la autonomía a la hora de gestionar su tiempo y su capacidad de jerarquizar labores, una pieza clave en los procesos de aprendizaje. De este modo se pretende la formación de jóvenes competentes dentro y fuera del ámbito académico, capaces de tomar decisiones, resolver problemas, adaptarse a distintos contextos de exigencia y a los constantes cambios que exige el mundo moderno [12]. Es posible que el paso de un espacio educativo protegido (enseñanza media), que se centra en la adquisición de contenidos, a otro espacio más centrado en la construcción autónoma de conocimiento sea un elemento condicionante del mal rendimiento de sujetos denominados tipológicamente como urbanos durante el primer semestre universitario.

Los estudiantes de las tipologías rurales (1 y 2) provenientes de localidades aledañas a la ciudad deben organizar tempranamente su tiempo y su vida en la ciudad, lo que permite mediar en el desarrollo de su capacidad de autogestión a nuevos ambientes y deben ser capaces de modificar su cultura originaria en favor de una adaptación rápida y efectiva.

La situación es especialmente notoria en sujetos que en ruralidad se clasifican en la tipología 2, puesto que se caracterizan por ser originarios de ciudades pequeñas, sus pueblos no poseen dependencia directa de la agricultura y tienen familias de mayor capital humano (padres universitarios), incluso por 
encima del promedio general de la tipología, lo que indica grupos de profesionales que se han movilizado fuera de las urbes en búsqueda de una vida más apacible y que aspiran a que sus hijos accedan a la universidad [13].

Existen múltiples explicaciones respecto a los resultados en el rendimiento de estos jóvenes, pero una de las más recurridas guarda relación con el fenómeno y la capacidad de autorregulación, situación altamente estudiada y que denota la existencia de una relación estrecha entre las estrategias de autorregulación del aprendizaje, el denominado 'enfoque profundo de aprendizaje' y las metas de dominio para el logro de buenos resultados académicos [14].

En la práctica, reconocer que el género no es un factor que origine desigualdades - por lo menos en lo que a rendimiento académico se refiere- y establecer una relación positiva entre ruralidad (origen socioacadémico) y rendimiento constituye un motor para avanzar hacia estudios más detallados que permitan establecer las probables estrategias de autorregulación y los enfoques de aprendizaje propios de estudiantes que proceden de una cultura con pensamiento y lógicas de tiempo-espacio diferentes.

Esto permitirá esclarecer cómo y cuándo se adquiere el estado de autorregulación y autogestión y cuáles son los factores que condicionan la aparición de estos enfoques de aprendizaje profundo en jóvenes de ambos géneros que provienen de comunas rurales.

El estudio busca contribuir a la generación de nuevas estrategias educativas que consideren las variables socioculturales de origen de los sujetos postulantes a las universidades y que permitan en el futuro mejorar el complejo escenario de quienes transitan desde la enseñanza secundaria a la universidad.
Bibliografía

1. Instituto Nacional de Estadísticas. Ciudades, pueblos, aldeas y caseríos. Santiago: INE, Departamento de Geografía y Censos; 2005.

2. OCDE Chile. OECD territorial reviews. Paris: Organization for Economic Cooperation and Development; 2009.

3. Saborío M, Rodríguez A. Exploración de gradientes de ruralidad y de las características urbano-rurales. In Rodríguez A, Saborío M, eds. Lo rural es diverso: evidencia para el caso de Costa Rica. San José: IICA; 2007.

4. Berdegué J, Jara E, Modrego F, Sanclemente X, Schejtman A. Comunas rurales de Chile. Documento de trabajo n. ${ }^{\circ} 60$. Programa Dinámicas Territoriales Rurales. Santiago: Rimisp; 2010.

5. Camarero FJ, Martín F, Herrero J. Estilos y estrategias de aprendizaje en estudiantes universitarios. Psicothema 2000; 12: 615-22.

6. Latham G, Green P. The journey to university: a study of 'the first year experience.' Melbourne: Royal Melbourne Institute of Technology. URL: http://ultibase.rmit.edu.au/Articles/ dec97/greenlath1.htm.

7. Zar JH. Biostatistical analysis. 3 ed. New Jersey: Prentice-Hall; 2006.

8. Vélez van Meerbeke A, Roa-González CN. Factores asociados al rendimiento académico en estudiantes de medicina. Educ Med 2005; 8: 74-82.

9. Carrión-Pérez E. Validación de características al ingreso como predictores del rendimiento académico en la carrera de medicina. Rev Cubana Educ Med Super 2002; 16: 5-18.

10. Padierna-Luna JL, Oseguera-Rodríguez J, Guidiño-Hernández $\mathrm{N}$. Factores socioacadémicos, estilos de aprendizaje, nivel intelectual y su relación con el rendimiento académico previo de médicos internos de pregrado. Educ Med 2009; 12: 91-102.

11. Beguet B, Cortada de Kohan N, Castro A, Renault G. Factores que intervienen en el rendimiento académico de los estudiantes de psicología y psicopedagogía. Revista Científica de la Dirección de Evaluación y Acreditación de la Secretaría General de la Universidad del Salvador-USAL 2001; 1.

12. Enríquez A, Rentería E. Estrategias de aprendizaje para la empleabilidad en el mercado de trabajo de profesionales recién egresados. Universitas Psychologica 2007; 6: 89-103.

13. Osses P, Foster W, Núñez R. Medición de niveles de ruralidad y su relación con las actividades económicas en la X Región de los Lagos-Chile. Enfoque geográfico-económico. Economía Agraria 2006; 10: 107-18.

14. Pérez MV, Valenzuela MF, Díaz A, González JA, Núñez JC Disposición y enfoques de aprendizaje en estudiantes universitarios de primer año. Universitas Psychologica 2011; 10: 441-50. 